\title{
CYTOKINES AND MOTHER SPOROCYSTS IN SUSCEPTIBLE AND RESISTANT BULINUS TRUNCATUS SNAILS INFECTED WITH SCHISTOSOMA HAEMATOBIUM
}

\section{By}

\author{
ABDEL HAKIM SAAD EL-DIN ${ }^{1}$, FATHIYA ALI GAWISH ${ }^{2}$, HANAA MOHAMED ABU \\ EL EININ $^{2}$ AND SHEREEN MAHFOUZ MANSOUR ${ }^{2}$ \\ Department of Zoology ${ }^{1}$, Faculty of Science, Cairo University, Giza, \\ Department of Environmental Research and Medical Malacology ${ }^{2}$, Theodor Bilharz \\ Research Institute, PO Box 30, Imbaba, Giza, Egypt. \\ Corresponding author E-mail: hanaamohamed_1@yahoo.com
}

\section{Abstract}

The presence of immunoreactive interleukin (IL-2), interferon gamma (IFN- $\gamma$ ) and tumor necrosis factor alpha (TNF- $\alpha$ ) in addition to the citation of mother sporscytes in cephalopodal musculature in the susceptible and resistance Bulinus truncatus the specific intermediate host for the trematode Schistosoma haematobium were investigated,. Using ELISA tests, Results indicated that the concentration of IL-2-like activity in the susceptible and resistant snails decreased significantly after infection then persisted at low levels until the $4^{\text {th }}$ week post exposure (WPE) in susceptible snails, while in resistant snails elevated during the second WPE, and returned to initial level at 3 and 4 WPE. Susceptible snails had low detectable levels of TNF- $\alpha$ and INF- $\gamma$ like-activity after infection. However, the resistant snails had significant low levels of TNF- $\alpha$ and INF- $\gamma$ like-activity from 3 WPE until the 4th WPE without any sign of normalization. Histological sections in the head- foot region of susceptible and resistance $B$. truncatus infected with S. haematobium, mother sporocysts exists from1 to 7(day post exposure) DPE, in the susceptible snail the mother sporocysts were found as single, multiple and mature types. No mother sporocysts were appear in the lip and mantle of the snail on 2, 5, 7 DPE and on 1-3, 6 DPE respectively. In the resistant snails few mother sporocysts were found in the lip, mantle and tentacles. The results showed that schistosome-resistant Bulinus can be an alternative strategy for the control of schistosomiasis.

Key words: Bulinus truncatus, cytokine Schistosoma haematobium, sporocyst, susceptible, resistant.

\section{Introduction}

Schistosomiasis is a chronic debilitating disease in tropical regions of Africa, Americas and Asia. The relationships between schistosomiasis and its intermediate host, mollusks of the genus Biomphalaria and Bulinus have been a concern for decades. It is known that the vector mollusk shows different susceptibility against the parasite infection, whose occurrence depends on the interaction between the forms of trematode larvae and the host defense cell (Oliveira et al, 2010).

Cytokines or interleukins (IL) are soluble mediators that regulate the effectors phase of immune responses. For instance, interleukin (IL)-1 is described as a cytokine when it mediates the interaction between the macrophages and $\mathrm{T}$ lymphocytes Ottaviani
(2006). These molecules appear very early during evolution (Ottaviani et al., 1995). Cytokines-like molecules are found in several invertebrates, such as molluscs (Granath et al, 1994; Ouwe-Missi-OukemBoyer et al, 1994; Ottaviani et al, 1995, Ottaviani, 2006, Steelman and Connors, 2009), insects (Beck and Habicht, 1994), annelids (Cooper et al, 1995). Cytokine immunoreactive molecules was detected in different tissues of mollusks (Ottaviani, 2006). Using different technical approaches, these molecules have been detected in immunocytes, hemolymph, eggs, embryos, larvae, neurons and glial cells from gastropods and bivalves (Hughes et al, 1990, 1992; Stefano et al, 1991; Paeman et al, 1989; Ottaviani et al, 2000). IL-1 and tumor necrosis factor alpha (TNF- $\alpha)$ Granath et al. 
(1994), Owe-Missi-Oukem-Boyer et al. (1994), has been detected in Biomphalaria glabrata the intermediate host for the human blood fluke, Schistosoma mansoni.

The presence of IL- $1 \alpha$ and $\beta$, IL- 6 and TNF- $\alpha$-like molecules were demonstrated in hemocytes of Planorbarius corneus and Viviparus ater (Ottaviani et al, 1993; 1995). Molluscan hemocytes might produce these cytokines as they showed immunostaining with antisera raised against cytokines from vertebrates (Ottaviani et al, 1993). They have been conserved during evolution. Molluscan hemocytes respond to human cytokines in manner similar to human granulocytes. This effect can block by prior treatment with anti-cytokines molecules, suggesting they are mediated by specific surface receptors (Clatworthy, 1996). It is generally accepted that the action of cytokines results from their binding to specific receptors. However, many cytokines possess lectin-like activity essential for expression of their full biological activities. TNF may represent an essential recognition mechanism that functionally conserved during the innate immune response of invertebrates and vertebrates as a result of convergent evolution (Beschin et al, 2004).

The numerous species, strains of Biomphalaria and Bulinus vary in their compatibility as a schistosome host such that some display resistance to infection while others are susceptible. In the Biomphalaria, when resistant snails are exposed to $S$. mansoni miracidia, hemocytes (snail blood cells) migrate towards the recently transformed sporocysts and enclose them in a multilayered cellular encapsulation. Soon after, the sporocysts are killed by a cytotoxic reaction which most likely involves free radicals such as hydrogen peroxide and/or nitric oxide (Hahn et al. 2001). In contrast, susceptible snails are not able to successfully defend against $S$. mansoni larvae and an infection will develop following miracidial exposure. After penetrating the head/foot region of the susceptible snails, schistosome miracidia transform into sporocysts. Then, second generation sporocysts known as daughters develop inside the first generation sporocysts through polyembryony. Larvae remain in the head/foot region for approximately 2-3 weeks, after which they can be found in the digestive gland-gonad (DGG) complex where they continue to multiply. When the infection reaches patency at approximately 4 weeks post infection, cercariae are released from daughter sporocysts and are released from the snail.

In this work, the presence of immunoreactive interleukin (IL-2), interferon gamma (IFN- $\gamma$ ) and tumor necrosis factor alpha (TNF- $\alpha$ ) in the susceptible and resistance $B$. truncatus, specific intermediate host for trematode $S$. haematobium were investigated weekly after infection in additions, locations of mother sporocysts were determined daily in head-foot region of snails.

\section{Materials and Methods}

Snails and exposure to infection: Laboratory-reared, adults Bulinus truncates (6-10 mm shell height) and miracidia of Schistosoma haematobium were supplied by Schistosome Biological Supply Center [SBSC, Theodor Bilharz Research Institute (TBRI), Giza, Egypt]. Snails were maintained as described by Liang et al. (1987). Bulinus trancatus snails were exposed individually, for $3 \mathrm{hr}$, in $1 \mathrm{ml}$ dechlorinated water, to 5-10 freshly $S$. haematobium miracidia. Exposed snails were examined daily for cercarial shedding by exposing them to fluorescent light for 2 $\mathrm{hr}$ form the first week up to 6 weeks. Snails were classified into susceptible and resistant according to Lewis et al (1993).

The collection of hemolymph from different groups of B. truncatus at 1, 2, 3 and 4 WPE to $S$. haematobium miracidia was essentially as described by El-Dafrawy et al. (2006). Water adhering to the snail was removed and the foot was cleaned with tissue paper. By touching the head-foot with 
the point of Pasteur pipette, the snail was forced to retract deeply into the shell and extruded hemolymph. In this way, as much as 5-20 $\mu$ l of hemolymph was obtained from susceptible and resistant snails, respectively (Mansour et al., 1995; Negm et al, 1995). Hemolymph collected from randomly selected 8-15 snails, in each specified group, was pooled in siliconized glass tubes at $4^{\circ} \mathrm{C}$ to prevent clumping and adherence of hemocytes. Aliquots of pooled hemolymph were freed of hemocytes by centrifugation for 10 min at $150 \mathrm{XG}$ and used for further analysis.

The production of IL-2, TNF- $\alpha$ and IFN- $\gamma$ in hemolymph were measured by enzyme linked immunosorbant assay (ELISA). ELISA depended on the adsorption of specific antibody $(\mathrm{Ab})$ onto the surface of a solid phase (microtiter plate). Addition of test samples thought to contain cytokine results in the formation of specific complexes which can be labeled with enzyme-conjugated anti-cytokine. When a suitable substrate is added hydrolysis results, the degree of which is proportional to the amount of attached enzyme. The enzyme and substrate are chosen so that the product of enzyme-substrate breakdown is colored. The depth of the color can then be assayed spectrophotometrically at appropriate wave length. The intensity of colored end product provided a measure of the cytokine concentration.

Purified mouse anti-human IL monoclonal antibodies (Pharmingen, San Diego, CA, USA ) was diluted V/V ( 1:1000) with $\mathrm{Na}_{2}$ $\mathrm{CO}_{3}-\mathrm{NaHCO}_{3}$ coating buffer $0.224 \mathrm{M}, \mathrm{pH}$ 9.6 and the polystyrene 96-well flat-bottom microtiter plate (Nunc) was coated with 100 $\mu \mathrm{l} /$ well of coating solution, covered and incubated-overnight in humidified chamber at $4{ }^{\circ} \mathrm{C}$, the coating solution was aspirated from the wells and the plate was washed for 3 times with washing buffer. The plates were dried by $200 \mu \mathrm{l}$ of PBS $/ 0.05 \%$ Tw, $3 \%$ BSA. The plate was incubated at $37^{\circ} \mathrm{C}$ for 2 hr. After washing, the standards and dilute samples $[1: 10(\mathrm{v} / \mathrm{v})]$ were added $(50 \mu \mathrm{l} /$ well $)$ and incubated for $1 \mathrm{hr}$ at room temperature. At the end of incubation period, plate was washed as mentioned before. $50 \mu 1$ of diluted second antibody $[1 \mu \mathrm{g} / \mathrm{ml}$ biotinylated rat anti-human-IL (Pharmingen)] were added into each well and incubated for $1 \mathrm{hr}$. The plate was then washed 4 times and $50 \mu \mathrm{l} /$ well of peroxidase conjugated streptavidine $(1: 1000)$ were added and incubated for $1 \mathrm{hr}$ at $37^{0} \mathrm{C}$ with shaking. The plate was rinsed 4 times with washing buffer and $100 \mu$ of freshly prepared peroxidase substrate solution with equal volume of TMP and $\mathrm{H}_{2} \mathrm{O}_{2}$ were added. The color developed within $10 \mathrm{~min}$. the reaction was stopped with $50 \mu \mathrm{l} /$ well of stopping reagent (2N HCL) and the absorbance was measured at $450 \mathrm{~nm}$ by UV max ELISA reader (molecular Devices Crop).

Light microscopy: To study parasite development, at each time of testing, infected and uninfected snails were initially relaxed with menthol crystals (approximately $\left.2 \times 10^{-4} \mathrm{M}\right)$. Each snail was then carefully crushed between two microscope slides, and the broken shell was pulled away from the body. The columellar muscle was separated from the shell, and the snail was extracted intact. Snails from susceptible and resistant strains were fixed in Bouin's fixative for at least $24 \mathrm{hr}$ and then placed in gradually increasing the concentrations of ethanol. Hematoxylin-eosin-stained $5-\mu \mathrm{m}$ sections in foot, head, lip, mantle and tenticles were examined microscopically for the number and histological condition of larval trematodes, as categorized by Borges et al. (1998). Histological analysis was performed on about 38 and 45 susceptible and resistant snails, respectively.

Statistical analysis: Data was analyzed using the State Most Software (Data Most Corporation, Salt Lake City, Utah). Experimental data was separated into two groups; a control and an experimental group. Differences between means at different intervals post-infection were tested using the analysis of variance (ANOVA). When di- 
fferences were found statistically significant $(\mathrm{P}<0.05)$, individual means were then compared with Students t-test by SPSS program.

\section{Results}

Fig. (1-A) indicated that the concentration of IL-2-like activity in the susceptible snails decreased significantly between the 1-3 WPE, and persisted at low levels until the $4^{\text {th }}$ WPE. While, the concentration of IL-2 in the resistant snails decreased significantly at 1 WPE, elevated during the second WPE, and returned to initial level at 3 and 4 WPE. On the other hand, the levels of TNF- $\alpha$ and INF- $\gamma$ like-activity during the course of infection shows that: A significant low level comparable to resistant snails was observed at 4 WPE. But, resistant snails had significant low levels of TNF- $\alpha$ and INF- $\gamma$ likeactivity from 3 WPE until $4^{\text {th }}$ WPE without any sign of normalization (Fig.1-B\&C).

Citation of mother sporocysts in head-foot region of Bulinus truncatus: Presences or absences of mother sporocysts in cephalopodal musculature of susceptible (S) and resistant (R) B. truncatus individually exposed to miracidia of Schistosoma haematobium conducted from 1 to 7 days postexposure (DPE) (Tab. 1). Histological section shows that: In the susceptible snails mother sporocysts were appear clearly in the anterior surface of the foot, head, lip and mantle at 1, 2, 5 ,7 DPE, 1, 3 , 6 DPE , 1,4, $6 \mathrm{DPE}$ and at 2, 4, 5 DPE respectively.

In the posterior surface of the foot a few of them were found on 6 DPE. Both in the posterior surface of head and lip mother sporocysts were found on 3 DPE and on mantle on 6 and 7 DPE. On the both surfaces of these tissues, many of the mother sporocysts were appear at 3 and 4 DPE in the foot, At 4 and 6 DPE on the head and At 4 DPE on the lip and mantle. In the foothead region of the snail's mother sporocysts exists from 1 to $7 \mathrm{DPE}$. But, no mother sporocysts appeared in the lip and mantle of the snail on 2, 5, 7 DPE. and on 1, 3 DPE respectively. In the tentacles of susceptible snails, mother sporocysts were visible in the body and base of the tentacles of the snails. In the body, mother sporocysts were observed at 1,2, 3 and 4 DPE and in the apex of the tentacles a few mother sporocysts were visible on 6 DPE only. Mother sporocysts remained in the snails' tentacles from 1 to 7 DPE. In all organs of susceptible snails the mother sporocysts were found as single, multiple and mature types (Tab. 1). In the susceptible snails most of the mother sporocysts grew further in the foot, head, tentacles, mantle and developed into the mature form at 5 DPE onward and after one week of infection, some mature mother sporocysts were observed in the foot, head, lip and tentacles, tegument of mature mother sporocyst was ruptured due to the increase number, and size of the embryos, and a few of them migrated towards the deeper tissues of the organs of snails' body.

In the resistant snails few mother sporocysts were found on the anterior surface of the foot at 1,3 and 6 DPE and on the posterior surface on 3 and 7 DPE. On both surface of the foot of resistant snails, they were observed on 3 DPE. No mother sporocysts were seen on the foot of these snails 2, 4 and 5 DPE. In the head a few mother sporocyst were found only on the anterior surface of the head at $4 \& 7 \mathrm{DPE}$, whereas, a single mother sporocyst was found only on the lip anterior surface of resistant snails at 7 DPE. Mother sporocyst was found only on the anterior surface of the mantle of the resistant snails at 7 DPE. On posterior mantle surface of these snails, mother sporocyst was found on $5 \& 6$ DPE. In tentacles of resistant ones, mother sporocysts were found in body on 2, 5 DPE, and in base only at 1 DPE. 

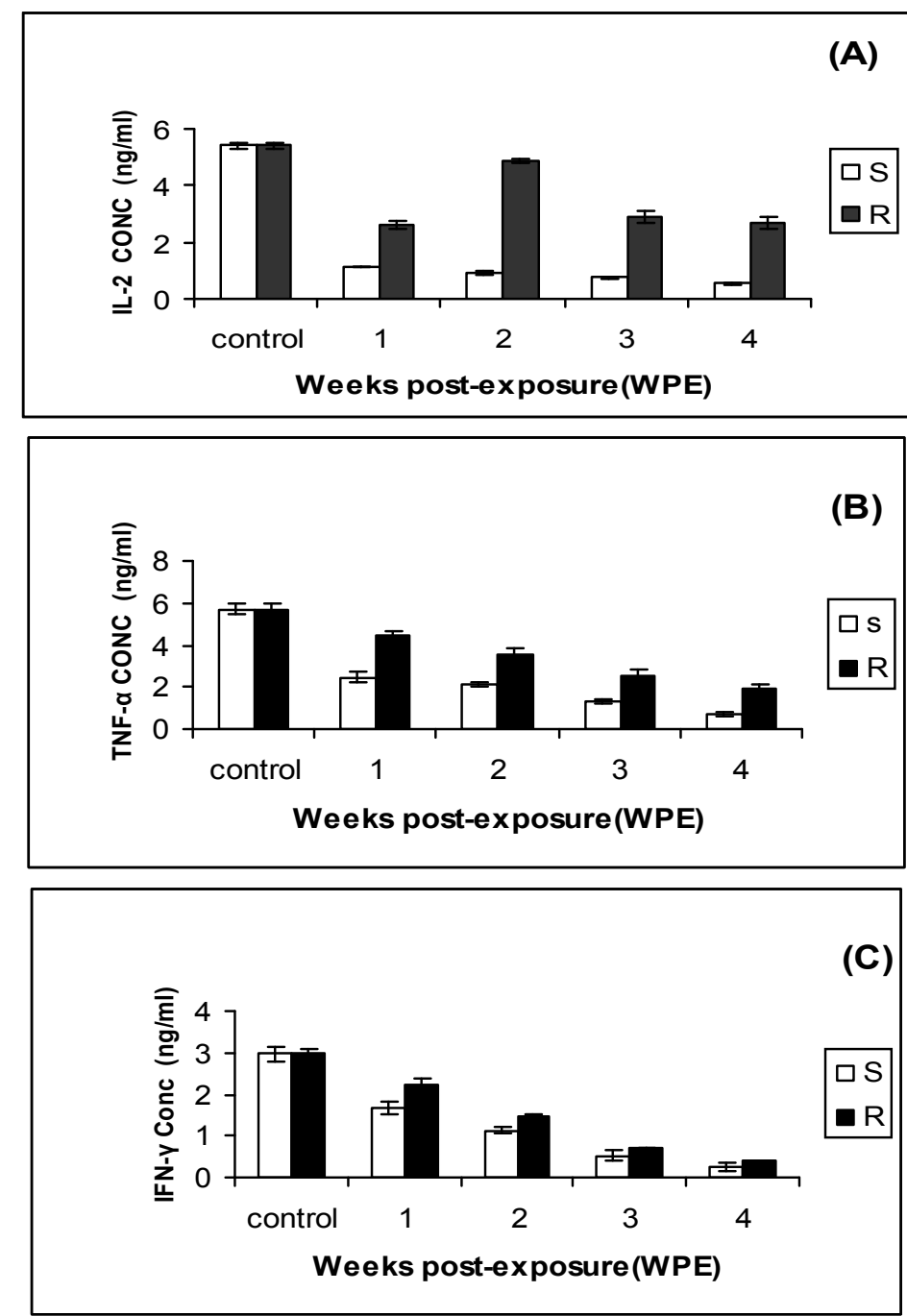

Fig. 1: Time course analysis of IL-2 (A), TNF- $\alpha$ (B) and IFN- $\gamma(\mathrm{C})$ in hemolymph from susceptible (S) and resistant (R) B. truncatus snails. Each point represents mean level of data collected from at least 8-15 Specimens \pm SE. Post-exposure values are significantly different from pre-exposure values $(\mathrm{P}<0.05)$.

Table 1: Presences or absences of mother sporocysts in cephalopodal musculature of susceptible (S) and resistant (R) Bulinus truncates snail.

\begin{tabular}{|c|c|c|c|c|c|c|c|c|c|c|c|c|}
\hline \multirow{2}{*}{$\begin{array}{l}\text { Days post ex- } \\
\text { posure (DPE) }\end{array}$} & \multirow[t]{2}{*}{ Snails } & \multicolumn{2}{|c|}{ Foot } & \multicolumn{2}{|c|}{ Head } & \multicolumn{2}{|c|}{ Lip } & \multicolumn{2}{|c|}{ Mantle } & \multicolumn{3}{|c|}{ Tentacles } \\
\hline & & Ant & Post & Ant & Post & Ant & Post & Ant & Post & Apex & Body & Base \\
\hline \multirow[t]{2}{*}{1} & $\mathrm{~S}$ & + & - & + & - & + & - & - & - & - & + & + \\
\hline & $\mathrm{R}$ & + & - & - & - & - & - & - & - & - & - & + \\
\hline \multirow[t]{2}{*}{2} & $\mathrm{~S}$ & + & - & - & - & - & - & + & - & - & + & + \\
\hline & $\mathrm{R}$ & - & - & - & - & - & - & - & - & - & + & - \\
\hline \multirow[t]{2}{*}{3} & $\mathrm{~S}$ & + & + & + & + & - & + & - & - & - & + & + \\
\hline & $\mathrm{R}$ & + & + & - & - & - & - & - & - & - & - & - \\
\hline \multirow[t]{2}{*}{4} & $\mathrm{~S}$ & + & + & + & + & + & + & + & + & - & + & + \\
\hline & $\mathrm{R}$ & - & - & + & - & - & - & - & - & - & - & - \\
\hline \multirow[t]{2}{*}{5} & $\mathrm{~S}$ & + & - & - & - & - & - & + & - & - & - & + \\
\hline & $\mathrm{R}$ & - & - & - & - & - & - & - & + & - & + & - \\
\hline \multirow[t]{2}{*}{6} & $\mathrm{~S}$ & - & + & + & + & + & - & - & + & + & + & + \\
\hline & $\mathrm{R}$ & + & - & - & - & - & - & - & + & - & - & - \\
\hline \multirow[t]{2}{*}{7} & $\mathrm{~S}$ & + & - & - & - & - & - & - & + & - & + & + \\
\hline & $\mathrm{R}$ & - & + & + & - & + & - & + & - & - & - & - \\
\hline
\end{tabular}

+ Present, Ant: Anterior - Absences, Post: posterior 


\section{Discussion}

The presence of different pleiotropic cytokines (IL-1, IL-2, IL-6 and TNF- $\alpha$-like molecules) in gastropod molluscs and their role in immunoregulation have been investigated by (Ouwe-Missi-Oukem-Boyer et al, 1994; Beck and Habicht, 1994; Ottaviani et al, 1994; 1995; Granath et al, 1994; Saad, 1995; Ottaviani, 2006; Steelman and Connors, 2009). However, to the authors knowledge no evidence concerning the presence of other cytokine (e.g. IFN- $\gamma$ )-like activity in gastropod molluscs have been investigated. The central role played by the present cytokines in inflammation and its involvement in pathological processes such as parasitic infection has led us to search for the presence of Il-2, INF- $\alpha$ and INF- $\gamma$-like mediators in Bulinus truncates snail.

As a preliminary step toward the demonstration of a possible relevance of components in the host-parasite relationship the modulation of their levels during the establishment of $S$. haematobium in $B$. truncates were investigated. In the present result, hemolymph that collected from resistant snails contained higher amounts of TNF- $\alpha$ as compared to susceptible snails. A significant inhibition of this secretion, particularly in susceptible snails occurred very early (1-2 WPE) following the miracidial penetration and persisted during the 3 WPE, that is, the period required to induce maturation of the parasites and differentiation into cercarial larvae. In contrast, quantification of IFN- $\gamma$ by ELISA demonstrated the presence of lower levels in susceptible snail hemolymph as compared to healthy and resistant snails. A significant decrease of this secretion, in resistant snails, occurred during the miracidial penetration phase and persisted until 3 WPE. However, it has been shown that this is not the case in the level of IL-2 in susceptible stock of $B$. runcatus. A significant inhibition of level occurred very early (1-2 WPE), persisted until the 3-4 WPE. In the present work, direct evidence concerning the IL-2 like activity has been obtained in resistant snails. However, the modulation of their levels during $S$. haematobium infection suggests that (Th2 cytokines) can play a role in $B$. truncatus immune functions and hostparasite relationships.

Lodes et al. (1991) and Yoshino and Vasta (1996) showed that resistance to schistosome infection in the snail is likely to be the result of a complex process involving a variety of mechanisms that act in a cumulative or quantitative manner to result in incompatibility and killing within the snail. Based upon our studies, it can be hypothesized that upon entering a susceptible snail, the schistosome releases a number of excretory/ secretory (E/S) products that selectively and cumulatively affect the ability of the snail to recognize and respond to the parasite (Lodes and Yoshino, 1990; Lodes et al, 1991; Granath et al, 1994; Connors et al, 1995). In resistant snails, on the other hand, the effects of released parasite products would differ depending on the snail strain infected. In resistant 10-R2 snails, parasite products would not sufficiently interfere with cytokine levels and hemocyte function to prevent the adequate activation or upregulation of the killing mechanism (Granath et al, 1994; Connors et al, 1995; 1998). Parasite death would occur in this strain even though several hemocyte activities are adversely affected by the parasite because the cumulative effects of the parasite on the various hemocyte activities and defense-related functions would be quantitatively insufficient to block killing completely, possibly as the result of the significantly larger number of circulating hemocytes in these snails relative to the susceptible M-lines (Lodes et al, 1991; Granath et al, 1994). Conversely, in resistant 13-16-R1 snails, parasite molecules or parasite contact would trigger the elevation of cytokine levels, resulting, in the rapid activation of the cellular and humoral 
mechanisms that result in the killing and elimination of the sporocysts (Connors et al, 1990, 1995, 1998). Corr^ea el al. (2012) reported that, the susceptibility level of the mollusc has been attributed to the capacity of internal defense system (IDS)-hemocytes and soluble components of the hemolymphto recognize and destroy the parasite.

The development of $S$. mansoni inside the intermediate host starts immediately after the active penetration of the snail by the miracidium, after penetration, the parasite undergoes morphological and physiological changes, being transformed into primary sporocyst (or mother sporocyst) that remains in the fibromuscular tissue of the host's cephalopodal region, near the penetration site. After 2- 3 weeks, primary sporocysts generate secondary ones (or daughter sporocysts), which migrate from the cephalopodal musculature to the digestive glands or hepatopancreas of the mollusc, where their germinative cells can generate the cercariae (Pereira et al, 1984). In the susceptible snails four or five mother sporocytsts developed normally when exposed to 25 miracidia after $24 \mathrm{hr}$ of infection (Niemann and lewis, 1990; Cooper et al, 1994; Théron and Coustau, 2005).

In the present work, many mother sporocysts developed in the foot, head, of the susceptible snail individually exposed to miracidia of $S$. haematobium after 1-2 DPE, These findings are in close agreement with, (Sullivan and Hu, 1996; Ateav et al, 1997; El-Ansary, and Al-Daihan 2006, Kalhoro et $a l, 2007)$. However, mother sporocysts were also detected in the lip, mantle and tentacles of the susceptible B. truncatus snails. Mother sporocysts have been reported in the tentacles of the snails by Wajdi (1966). Ateav et al. (1997) found that mother sporocysts of E. caproni developed in the mantle epithelium of the B. pfeifferi snails. Kalhoro et al. (2007) reported 2 to 9 mother sporocysts in the columellar muscles of the B. glabrata snails. However, in the present study, a few mother sporocysts were also found in the columellar muscle of the resistant snails at 7 DPE.

\section{Conclusion}

The schistosome-resistant Bulinus can be an alternative strategy for the control of schistosomiasis by discus and quantify of the various factors in the internal defense system that cumulatively and quantitatively contribute to parasite death or survival, including the identification, isolation and sequencing of snail cytokine-like molecules and their precursors.

\section{References}

Ataev, GL, Uobrovolskij, AI, Ournier, AF, Jourdane, J, 1997: Migration and development of mother sporocysts of Echinostoma caproni (Digenea: Echinostomatidae). J. Parasitol. 83, 444-53

Beschin A, Bilej M, Magez S, Lucas R, De Baetselier P, 2004: Functional convergence of invertebrate and vertebrate cytokine-like molecules based on a similar lectin-like activity. Prog. Mol. Subcell Biol. 34:145-63.

Beck, G, Habicht, GS, 1994: Invertebrate cytokines. Ann. N.Y. Acad. Sci. 712:206-212.

Borges, CM, Souza, CP, Andrade, ZA, 1998: Histopathological features associated with susceptibility and resistance of Biomphalaria snails to infection with Schistosoma mansoni. Mem. Inst. Oswaldo Cruz 93:117-21.

Clatworthy, AL, 1996: A simple systems approach to neural-immune communication. Comp. Physiol. 115:1-10.

Connors, VA, Yoshino, TP, 1990: In vitro effect of larval Schistosoma mansoni excretory-secretory products on phagocytosis-stimulated superoxide production in hemocytes from Biomphalaria glabrata. J. Parasitol. 78:895-902

Connors, VA, de Buron, I, Granath, WO, 1995: Schistosoma mansoni: Interleukin-1 increases phagocytosis and superoxide production by hemocytes and decreases output of cercariae in schistosomesusceptible Biomphalaria glabrata. Exp. Parasitol. 8:139-48.

Connors, VA, de Buron, I, Jourdane, J, Theron, A, Agner, A, Granath, WO, 1998: Recombinant human interleukin-1- mediated killing of Schistosoma mansoni primary sporocysts in Biomphalaria glabrata. J. Parasitol. 84:920-6.

Cooper, EL, Richards, C, Lewis, F, Minchella, D, 1994: Schistosoma mansoni: Relationship between low fecundity and reduced susceptibility to 
parasite infection in the snail, Biomphalaria glabrata. Exp. Parasitol. 79:21-8.

Cooper, EL, Franchini, A, Ottaviani, E, 1995: Earthworm coelomocytes possess immunoreactive cytokines and POMC- derived peptides. Anim. Boil. 4:25-9.

Corrêa, ND, Mattos, AC, Pereira CA, Martins-Souza RL, Coelho PM, 2012: Interaction of Schistosoma mansoni sporocysts and hemocytes of Biomphalaria. J. Parasitol. Res. 743920, 1-

El-Ansary, A, Al-Daihan, S, 2006: Important aspects of Biomphalaria snail-Schistosoma interactions as targets for anti-schistosome drug. Med. Sci. Monit. 12:282-92.

El-Dafrawy, S, Sharaf El-Din, A, Hamid, HA, 2006: Electrophoretic patterns of protein fractionations in hemolymph and tissues of Biomphalaria alexandrina and Bulinus truncatus during course of schistosome infection. J. Egypt. Soc. Parasitol. 36:79-807.

Granath, WO, Connors, VA, Tarleton, RL, 1994: Interleukin-1 activity in hemolymph from strains of snail Biomphalaria galabrata varying in susceptibility to human blood fluk, Schistosoma mansoni: presence, differential expression and biological function. Cytokine 6: 21-7.

Hahn, U, Berder, R, Bayne, C, 2001: Killing of Schistosoma mansoni sporocysts by hemocytes from resistant Biomphalaria glabrata: role of reactive oxygen species. J. Parasitol. 87:292-9. Hughes, TK, Smith, EM, Cadet, P, Sinisterra, J, Leung, MK, et al, 1990: Interaction of immunoreactive monokines (IL- 1 and TNF- $\alpha$ ) in the bivalve mollusk Mytilus edulis. Proc. Natl. Acad. Sci. (USA), 87:4426-9.

Hughes, TK, Smith, E, Leung, M, Stefano, GB, 1992: Immunoreactive cytokines in Mytilus edulis: nervous and immune interactions. Acta Biol. Hung, 43:269-73.

Kalhoro, IB, Jalali, S, Sham, SA, 2007: Comparative study of the mother sporocyst of Schistosoma mansoni in the susceptible and resistant snails of Biomphalaria glabrata. J. Pakistan Vet. 27:80-4.

Lewis, FA, Richards, CS, Knight, M, Cooper, LA, Clark, B, 1993: Schistosoma mansoni: analysis of an unusual infection phenotype in the intermediate host snail Biomphalaria glabrata. Exp. Parasitol. 77: 349-61.

Liang YS, Bruce, JI, David AB, 1987: Laboratory cultivation of schistosome vector snails and maintenance of schistosome life cycles. Proce. $1^{\text {st }}$ Sino. Am. Symp. 1:34-8.
Lodes, MJ, Yoshino, TP, 1990: Effect of Schistosome excretory-secretory products on Biomphalaria glabrata hemocytes motility. J. Inverteb. Pathol. 56:75-85.

Lodes, MJ, Connors, VA, Yoshino, TP, 1991: Isolation and functional characterization of snail hemocyte-modulating polypeptide from primary sporocysts of Schistosoma mansoni. Mol. Biochem. Parasitol. 49:1-10.

Mansour, MH, Negm, H, Saad, AH, Taalab, N, 1995: Characterization of Biomphalaria alexandrina-derived lectinsrecogniaing a fucosyllactoserelated determinant on schistosomes. Mol. Biochem. Parasitol. 69:173-84.

Negm, H, Mansour, M, Saad, AH, Daoud, S, 1995: Defense mechanisms in adult and juvenile Biomphalaria alexandrina towards selective Schistosoma mansni glycoproteins. J. Egypt. Immunol. 1:163-76.

Niemann, G, Lewis, F, 1990: Schistosoma mansoni: Influence of Biomphalaria glabrata size on susceptibility to infection and resultant cercarial production. Exp. Parasitol. 70:286-92.

Oliveira, LM, Santos, HL, Goncalves, MM, Barreto, MG, Peralta, JM, 2010: Evaluation of polymerase chain reaction as an additional tool for the diagnosis of low-intensity Schistosoma mansoni infection. Diagn. Microb. Infect. Dis. 68:416-21.

Ottaviani E, 2006: Molluscan immunorecognition. Inv. Surv. J. 3:50-63.

Ottaviani E, 2005: Insect immunorecognition. Inv. Surv. J. 2:142-51.

Ottaviani, E, Caselgrandi, E, Franceschi, C, 1995: Cytokines and evolution: in vitro effects of IL-1 $\alpha$, IL-1 $\beta$, TNF- $\alpha$ and TNF- $\beta$ on an ancestral type of stress response. Biochem. Biophys. Res. Commun. 207:288-92.

Ottaviani, E, Caselgrandi, E, Franchini, A, Franceschi C, 1993: CRF provokes the release of norepinephrine from the hemocytes of Viviparus ater (Gastropoda, Prosobranchia): Further evidence in favor of the mobile immune brain. Biochem. Biophs. Ras. Comm. 193:446-52

Ottaviani, E, Franchini, A, Caselgrandi, E, Cossarizza, A, Franceschi, C, 1994: Relationship between corticotrophin-releasing factor and interleukin-2: evolutionary evidence. FEBS Lett. 351: 19-21.

Ottaviani, E, Franchini, A, Malagoli, D, Genedani, S, 2000: Immunomodulation by recom- 
binant human interleukin-8 and its signal transduction pathways in invertebrate hemocytes. Cell. Mol. Life Sci. 57:506-13.

Ouwe-Missi-Oukem-Boyer, O, Porchet, E, Capron, A, Dissous, C, 1994: Characterization of immunoreactive TNF- $\alpha$ molecule in the gastropod Biomphalaria glabrata. Dev. Comp. Immunol. 18: 211-8.

Paemen, LR, Porchet-Henner, E, Masson, M, Leung, M, Hughes, T, Stefano, GB, 1989: Glial localization of interleukin-1 $\alpha$ in inverte-brate ganglia. Cell Mol. Neurobiol. 12:463-71

Pereira, LH, Valadares, TE, Cunha, ML, Correa, MC, 1984: Recovery of young daughter sporocysts from snails infected with Schistosoma mansoni. Trans. Roy. Soc. Trop. Med. Hyg. 78:563-8.

Saad, AH, 1995: Invertebrate immunity.1. Effects of metenkephalin on in vitro phago-cytosis and IL1- like activity of Biompalaria alexandrina hemocytes. Proc. Zool. Soc. Egypt. 26:200-11.

Steelman, BN, Connors VA, 2009: Hemokinetic effect of interleukin-1 $\beta$ on cultured Biom- phalaria glabrata embryonic cells. J. Parasitol. 95:772-4

Stefano, GB, Smith, EM, Hughes, TK, 1991:

Opioid induction of immunoreactive interleukin-1 in Mytilus edulis and human immunocytes: an interleukin-1-like substance in invertebrate neural tissue. J. Neuroimmunol. 32:29-34

Sullivan, JT, Hu, PC, 1996: Fate of Schistosoma mansoni in Biompalaria obstructa. J. Parasitol. 82:743-7.

Théron, A, Coustau, C, 2005: Are Biomphalaria snails resistant to Schistosoma mansoni? J. Helminthol. 79:187-91.

Wajdi, N, 1966: Penetration by the miracidia of Schistosoma mansoni into the snail host. Helminthol. 40:235-44.

Yoshino, TP, Vasta, GR, 1996: Parasite-invertebrate host immune interactions. In: Invertebrate Immune Responses Cell Activities and the Environment: Advances in Comparative and Environmental Physiology. Cooper, E.L. (Ed.), 24, Springer-Verlag, Berlin. 